\title{
CHARACTERIZATION AND IN VITRO EXPRESSION OF THE CYTOCHROME $b-559$ GENES OF BARLEY. II. IN VITRO TRANSCRIPTION AND TRANSLATION
}

by

\author{
KARIN KRUPINSKA \\ Department of Physiology, Carlsberg Laboratory, \\ Gamle Carlsberg Vej 10, DK-2500 Copenhagen Valby \\ Present address: Botanisches Institut der Universität Kiel, \\ Olshausenstr. 40-60, D-2300 Kiel, FRG
}

Keywords: In vitro transcription, -translation, cytochrome $b-559$ apoproteins

\begin{abstract}
The two cytochrome $b-559$ aproproteins of $9.4 \mathrm{kD}$ and $4.5 \mathrm{kD}$ molecular weight have been expressed in vitro using DNA templates containing either the two genes psbE and psbF in tandem or the individual genes. Transcription with E. coli RNA-polymerase or SP6 RNA-polymerase has been followed by translation in E. coli derived lysates. Simultaneous as well as independent synthesis of the apoproteins is possible. A $9.4 \mathrm{kD}$ in vitro translation product has been identified as apoprotein I by immunoprecipitation with a monoclonal antibody specific for the C-terminal part of the $9.4 \mathrm{kD}$ apoprotein of cytochrome $b-559$. The isolated psbF gene directs the synthesis of a translation product with a molecular weight of $4.5 \mathrm{kD}$ corresponding to apoprotein II. Expression of the psbE gene requires the presence of endogenous regulatory sequences 5 ' upstream of psbE, while this is not the case for psbF. Additional in vitro translation products of 5.7 and $2.4 \mathrm{kD}$ molecular weights are synthesized and probably translated from two reading frames starting with two different out-of-phase ATG codons in the nucleotide sequence of the psbE gene.
\end{abstract}

\section{INTRODUCTION}

Cytochrome $b-559$ of thylakoid membranes is a $110 \mathrm{kD}$ lipoprotein complex with an apoprotein of $9.4 \mathrm{kD}$ and a second presumptive apoprotein of $4.5 \mathrm{kD}$ molecular weight. In spinach thylakoids both proteins occur in a $1: 1$ stoichiometry (21). A possible variation in the stoichiometry of the two proteins among plant species of different tissues or developmental stages is, however, not excluded. The genes coding for the two apoproteins, psbE and psbF, are bicistronically transcribed into a single mRNA species $(9,11)$. At present it is not known, if a coordinate synthesis of the corresponding proteins takes place or if a precursor polypeptide is made which subsequently is cleaved into the two polypeptides.

The psbE and psbF genes of barley chloroplasts were isolated and subcloned into appropriate expression vectors. In the present paper it

Abbreviations: $\mathrm{bp}=$ basepairs; $\mathrm{DTT}=$ dithiothreitol; $\mathrm{kbp}=$ kilobasepairs; $\mathrm{kD}=$ kilodalton; $\mathrm{mAb}=$ monoclonal antibody; Tris $=$ tris-(hydroxymethyl)-aminomethane. 
is shown that the two apoproteins can be synthesized in vitro in an E. coli derived lysate both when the mRNA is transcribed from a plasmid containing the natural arrangement of the two genes in tandem and when it is transcribed from separate plasmids with inserts covering one or the other gene.

\section{MATERIALS AND METHODS}

\subsection{Plasmids}

For in vitro expression DNA-fragments were subcloned into pDS6 (17) or pDS6-RBSII (kindly provided by Dr. D. STUEBER, Hoffmann La Roche, Basel). Like all plasmids of the pDS1family pDS6 is derived from pBR322 and has the strong coliphage promoter T5 (17). It is further specified by a terminator behind a region with multiple cloning sites. The modified vector pDS6-RBSII has a ribosomal binding site (RBS) inserted between the HindIII and BamHI sites of $\mathrm{pDS} 6$. This vector is therefore suitable for in vitro expression of transcripts without inherent ribosomal binding sites, if procaryotic systems are used for translation. For comparison, the Riboprobe Gemini ${ }^{\mathrm{TM}}$ transcription plasmid pGem3 (Promega Biotec) (13), which is commercially available, was used. The plasmid contains the two promoters SP6 and T7 both flanking a pUC18 derived polylinker region.

All expression vectors used contain the blagene for $\beta$-lactamase conferring ampicillin resistence to the bacterial host.

\subsection{Strains and media}

E. coli HB 101 was the recipient strain for the expression vectors pDS6, pDS6-RBSII and pGem3. The bacteria were prepared for transformation as described in part I (11). Minimal medium (12) supplied with $0.4 \%$ casamino acids and ampicillin $\left(100 \mu \mathrm{g} \times \mathrm{ml}^{-1}\right)$ was used to propagate bacteria with recombinant plasmids.

\subsection{Enzymes and chemicals}

Riboprobe SP6 RNA- and Riboprobe T7 RNA-polymerase were purchased from Promega Biotec (Madison, Wisconsin, USA). Bal31 exonuclease was obtained from IBI
(Newhaven, Conn., USA). All other enzymes were from Boehringer, Mannheim, FRG. ${ }^{35} \mathrm{~S}$ methionine and $\alpha-{ }^{35} \mathrm{~S}-\mathrm{dATP}$ as radioactive label in the sequencing reactions were obtained from New England Nuclear, USA. ${ }^{14} \mathrm{C}$-labelled methylated proteins used as molecular weight markers for autoradiographic characterization of gel-electrophoretically separated translation products were purchased from Amersham, UK.

\subsection{Preparation and analysis of recombinant plasmids}

DNA was isolated and purified as described in (11). The orientation of fragments inserted into pDS6, pDS6-RBSII and pGem 3 was checked by digesting the recombinant plasmid with appropriate restriction enzymes, or by sequencing with the dideoxy chain termination method of SANGER et al. (16) using synthetic 15-mer oligonucleotide primers complementary to the binding sites of the E. coli, SP6 and T7 RNApolymerases, respectively. Plasmid DNA was prepared for sequencing as described in (5).

\subsection{In vitro transcription}

In vitro transcription of DNA cloned into pDS6 or pDS6-RBSII was done according to STUEBER et al. (18) but without capping of the RNA. $2 \mu \mathrm{g}$ of supercoiled plasmid DNA were transcribed by 0.3 units of E. coli RNA-polymerase in a final volume of $10 \mu \mathrm{l}$ containing 20 mM-HEPES/KOH, pH 7.5, 10 mM-Mg-acetate, $200 \mathrm{~mm}$-K-acetate, $0.2 \mathrm{~mm}$-spermidine, $5 \mathrm{~mm}$ DTT, 10 units of RNasin (human placental RNase inhibitor, Boehringer) and $0.5 \mathrm{~mm}$ each of GTP, CTP, UTP and ATP. After 15 minutes incubation at $37^{\circ} \mathrm{C}$ the mixture was put on ice and was either directly used for translation assays or stored at $-20^{\circ} \mathrm{C}$.

Transcription of DNA cloned in pGem 3 was carried out according to the instructions of Promega Biotec either with SP6 RNA-polymerase or T7 RNA-polymerase using linearized plasmid DNA as templates. Before translation the assay was treated with DNase I ( $1 \mathrm{u} / \mu \mathrm{g} \mathrm{DNA})$ for 10 minutes at $37^{\circ} \mathrm{C}$ and then extracted with phenol and chloroform. The precipitated RNA was redissolved in water and stored at $-20^{\circ} \mathrm{C}$. 


\subsection{In vitro translation}

RNA obtained by in vitro transcription of cloned DNA-fragments was translated in an E. coli S30 lysate according to ZUBAY (22), prepared as described in PRITCHARD and HollaND (14) using the E. coli strain Y1090 or the strain PR7 (2).

Usually, a $50 \mu \mathrm{l}$ reaction mixture contained 5 $\mu l$ of the pDS6 transcription assay or one fourth of the pGem 3 transcription assay in $5 \mu \mathrm{I}$ water, $15 \mu \mathrm{l} \mathrm{S} 30$ extract, and $12.5 \mu \mathrm{l} 4 \times$ concentrated low molecular weight mix. To the translation assay was further added $5 \mathrm{mM}-\mathrm{Mg}$-acetate and $25 \mu \mathrm{Ci}{ }^{35} \mathrm{~S}$-methionine. The four times concentrated low molecular weight mix adjusted the reaction mixture to $44 \mathrm{~mm}$-Tris-acetate, $\mathrm{pH} 8.2$, $55 \mathrm{mM}$-K-acetate, $7.4 \mathrm{mM}$-Ca-acetate, $27 \mathrm{mM}$ $\mathrm{NH}_{4}$-acetate, $5 \mathrm{~mm}$-Mg-acetate, $30 \mu \mathrm{g} \times \mathrm{ml}^{-1}$ folinic acid, $0.1 \mathrm{mg} \times \mathrm{ml}^{-1}$ E. coli t-RNA, 2.2 mM-ATP, $0.55 \mathrm{~mm}$ each of GTP, UTP and CTP, $0.25 \mathrm{mM}$ of the 20 amino acids minus methionine, $1.4 \mathrm{mM}$-DTT, $21 \mathrm{~mm}$-phosphoenolpyruvate and $20 \%(w / v)$ polyethylenglycol.

\subsection{Immunoprecipitation}

${ }^{35} \mathrm{~S}$-methionine-labelled translation products were immunoprecipitated with the monoclonal antibody mAb 6A5 recognizing the C-terminal part of the $9.4 \mathrm{kD}$ polypeptide of cytochrome $b-559$ ((19) and O. VALLON, pers. commun.) and protein A-sepharose (Pharmacia) as described in Høyer-HANSEN et al. (10).

\subsection{Polyacrylamide-gel-electrophoresis}

In vitro synthesized products before and after immunoprecipitation were separated by electrophoresis on SDS containing $18 \%(\mathrm{w} / \mathrm{v})$ polyacrylamide gels using the high molarity Trisbuffer system of FLING and GREGERSON (7). After electrophoresis gels were transferred to $50 \%(\mathrm{v} / \mathrm{v})$ methanol and prepared for fluorography by soaking for 20 minutes in a solution of $20 \%(\mathrm{w} / \mathrm{v})$ sodium salicylate, $10 \%(\mathrm{v} / \mathrm{v})$ glycerol and $50 \%(\mathrm{v} / \mathrm{v})$ methanol (4). The dried gels were exposed to Kodak XAR X-Omat X-ray films at $-80^{\circ} \mathrm{C}$ using Kodak X-Omatic regular intensifying screens.

\section{RESULTS}

DNA-fragments containing either both cytochrome $b$-559 genes together or the individual psbE and psbF were inserted into the multiple cloning sites of the expression vectors pDS6 (18) and pGem 3 (Promega Biotec) (Figure 1). Transcripts made from pDS6 and pGem 3 were translated in an $\mathrm{S} 30$ lysate prepared from $\mathrm{E}$. coli cells $(14,22)$. Two different kinds of E. coli cells were used for preparing the lysate. While in the beginning E. coli strain Y1090 was used, later experiments were performed with an S30 lysate obtained from the E. coli strain PR7 (2).

Additionally, translation of pDS6 transcripts was tried in a commercially available rabbit reticulocyte lysate (Amersham) and in a wheat germ extract (kindly provided by SUSAN MADRID). Though, in these cases transcripts were "capped" by the addition of 7-methylguanosine triphosphate to the transcription mixture (18) no proteins were synthesized in the rabbit reticulocyte lysate and only low amounts of proteins were produced in the wheat germ extract (data not shown). S30 lysates prepared from intact chloroplasts (1) of spinach and barley did not show any protein synthesis due to exogenously added DNA or transcripts derived from pDS6 (data not shown).

\subsection{Concomitant expression of the two cytochrome $b-559$ genes}

For in vitro expression of psbE and psbF appropriate DNA-fragments containing both genes were isolated and subcloned into the expression vectors pDS6 and pGem 3 (Figure 1, Table I).

\subsubsection{0 bp Accl-BamHI fragment}

A 1150 bp DNA-fragment containing both genes and a 138 bp sequence 5' upstream of the psbE startcodon and noncoding DNA 3' downstream of psbF was isolated by digesting the 4.2 $\mathrm{kbp}$ BamHI fragment derived from $\mathrm{pHvC} 46$ (ref. 11, Figure 3) with Accl (Figure 1). The fragment was blunt-ended and subcloned into the SmaI site of pDS6. The orientation of the fragment with respect to the T5-promoter was determined by sequencing using a 15-mer 


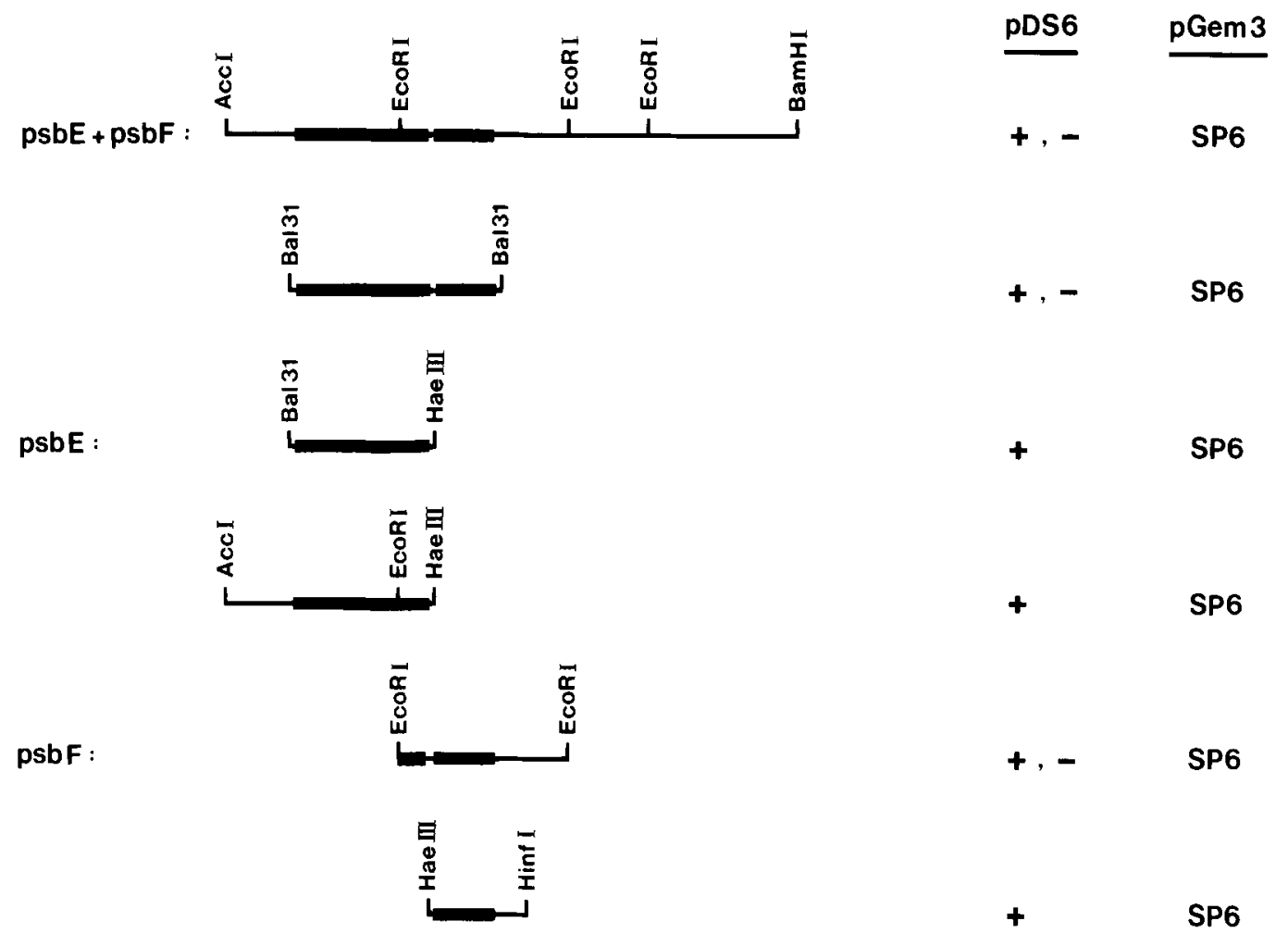

Figure 1. DNA-fragments containing either the two cytochrome $b-559$ genes together or the individual genes psbE and psbF. Endonuclease restriction enzymes and Bal 31 exonuclease used in isolation of the various fragments are indicated. EcoRI restriction sites given along the first fragment allow a comparison with the physical map of the pHvC 46 insert (ref. 11, Figure 3) and the nucleotide sequence (Figure 4).

The fragments were inserted into pDS6 in correct $(+)$ or inverse (-) orientation with respect to the $T 5$ promoter and transcribed by E. coli RNA polymerase. Fragments inserted into the twin promoter transcription vector pGem 3 were transcribed with both SP6 and T7 RNA-polymerase.

oligonucleotide complementary to the E. coli polymerase binding site as a primer. A recombinant pDS6 vector containing the insert in the correct orientation was compared to a vector with the insert in inverse orientation. The same fragment was also inserted into pGem 3 using the AccI and BamHI sites of the polylinker. SP6 RNA-polymerase had to be used for transcription of the genes. Transcription with T7 RNApolymerase was done as a control.

In vitro translation of transcripts derived from the recombinant pDS6 with the $1150 \mathrm{bp}$ insert was performed both in a S30 lysate from E. coli Y 1090 and a S30 lysate from strain PR7. The former gave considerable endogenous protein synthesis by itself and with transcripts from the vector without insert (Figure 2, two leftmost lanes) while the lysate from PR7 made only a few endogenous proteins with transcripts from the vector without inserts (Figure 2, lane 5). The recombinant pDS6 with the insert in correct orientation yielded with both lysates three polypeptide bands with sizes of $9 \mathrm{kD}, \sim 5$ $\mathrm{kD}$ and less than $5 \mathrm{kD}$ (Figure 2). If the vector contains the insert with reverse orientation the $9 \mathrm{kD}$ polypeptide is made in higher amounts and only traces of the smaller peptides can be detected. A monoclonal antibody (mAb 6A5) specific for the C-terminal part of the $9.4 \mathrm{kD}$ polypeptide of cytochrome $b-559$ ((19) and pers. com- 
Table I. Proteins synthesized by in vitro transcription/translation using recombinant pDS6 and pGem3 plasmids as templates. Inserts include either both cytochrome $b-559$ genes or individual psbE and psbF genes. The DNA fragments have been inserted into pDS6 either in correct $(+)$ or in inverse $(-)$ orientation with respect to the T5 promoter of the plasmid. DNA fragments inserted into pGem3 had to be transcribed with SP6 polymerase. Transcription with $\mathrm{T} 7$ polymerase was done as a control.

\begin{tabular}{|c|c|c|c|c|c|}
\hline \multirow[b]{2}{*}{ inserted DNA-fragment } & \multirow[b]{2}{*}{ genes } & \multicolumn{2}{|c|}{ pDS6 } & \multicolumn{2}{|c|}{ pGem3 } \\
\hline & & orientation & $\begin{array}{l}\text { molecular weight } \\
\text { of proteins }(k D)\end{array}$ & polymerase & $\begin{array}{l}\text { molecular weight } \\
\text { of proteins }(\mathrm{kD})\end{array}$ \\
\hline 1150 bp AccI-BamHI & $\mathrm{psbE}+\mathrm{F}$ & + & $9,5,4,2$ & SP6 & $9,5,4,(2)$ \\
\hline$"$ & $"$ & - & 9 & $\mathrm{~T} 7$ & - \\
\hline 400 bp Bal31 & $\mathrm{psbE}+\mathrm{F}$ & + & 4 & SP6 & $5,4,2$ \\
\hline$"$ & $"$ & - & - & T7 & - \\
\hline $400 \mathrm{bp} \mathrm{Bal} 31+36$ bp 5 ' extension & $"$ & + & 4 & & \\
\hline$"$ & $"$ & - & - & & \\
\hline 270 bp Bal31-HaelII & psbE & + & - & SP6 & - \\
\hline$"$ & $"$ & & & $\mathrm{~T} 7$ & - \\
\hline 370 bp Accl-HaeIII & $"$ & + & 9 & SP6 & 9 \\
\hline$"$ & $"$ & & & $\mathrm{~T} 7$ & - \\
\hline $350 \mathrm{bp}$ EcoRI & $\mathrm{psbF}$ & + & 4 & SP6 & 4 \\
\hline$"$ & $"$ & - & - & $\mathrm{T} 7$ & - \\
\hline 200 bp HaelII-Hinfl & $"$ & + & 4 & SP6 & - \\
\hline & $"$ & & & $\mathrm{~T} 7$ & - \\
\hline
\end{tabular}

mun.) was used for immunoprecipitation of the translation products. As seen in Figure 2, it recognized the $9 \mathrm{kD}$ polypeptide obtained by in vitro expression of the recombinant pDS6 clones with the insert in both orientations. Whereas immunoprecipitation of translation products obtained in the S30 extract of strain Y1090 included also several proteins due to endogenous protein synthesis when the insert was in the correct orientation, there is no comparable background with the insert in reverse orientation or if translates obtained in the E. coli PR7 lysate were immunoprecipitated (Figure 2). The fact that the $9 \mathrm{kD}$ immunoprecipitable cytochrome $b-559$ translate is obtained by inverse orientation of the insert indicates that transcription is from the chloroplast DNA promoter, included in the $1150 \mathrm{bp} \mathrm{AccI-BamHI}$ fragment (11).

Transcripts derived from $\mathrm{pGem} 3$ containing the $1150 \mathrm{bp}$ fragment in an orientation appropriate for the SP6 polymerase gave with this enzyme rise to the same three polypeptide bands as obtained with pDS6 (Figure 3). If instead of
SP6 RNA-polymerase T7 RNA-polymerase was used for transcription no vector transcript directed protein synthesis was observed in the two different E. coli S30 lysates used for translation (Figure 3). The monoclonal antibody (mAb $6 \mathrm{A5}$ ) recognized also in this case only the $9 \mathrm{kD}$ polypeptide.

\subsubsection{0 bp Bal31 fragment}

Partial digestion of the $1150 \mathrm{bp}$ AccI-BamHI fragment with HinfI releases a 470 bp fragment containing both genes and additional $40 \mathrm{bp} 5$, upstream of the psbE startcodon and $60 \mathrm{bp} \mathrm{3}$ ' downstream of the psbF stopcodon (Figure 4). The fragment was further treated with Bal31 exonuclease to reduce the number of noncoding nucleotides at both ends of the fragment. Various fragments obtained by this treatment were inserted into the SmaI site of pUC13 and sequenced. A $400 \mathrm{bp}$ fragment starting 12 nucleotides 5' upstream of the ATG-startcodon and including the putative ribosomal binding site, and ending 13 nucleotides beyond the psbF 


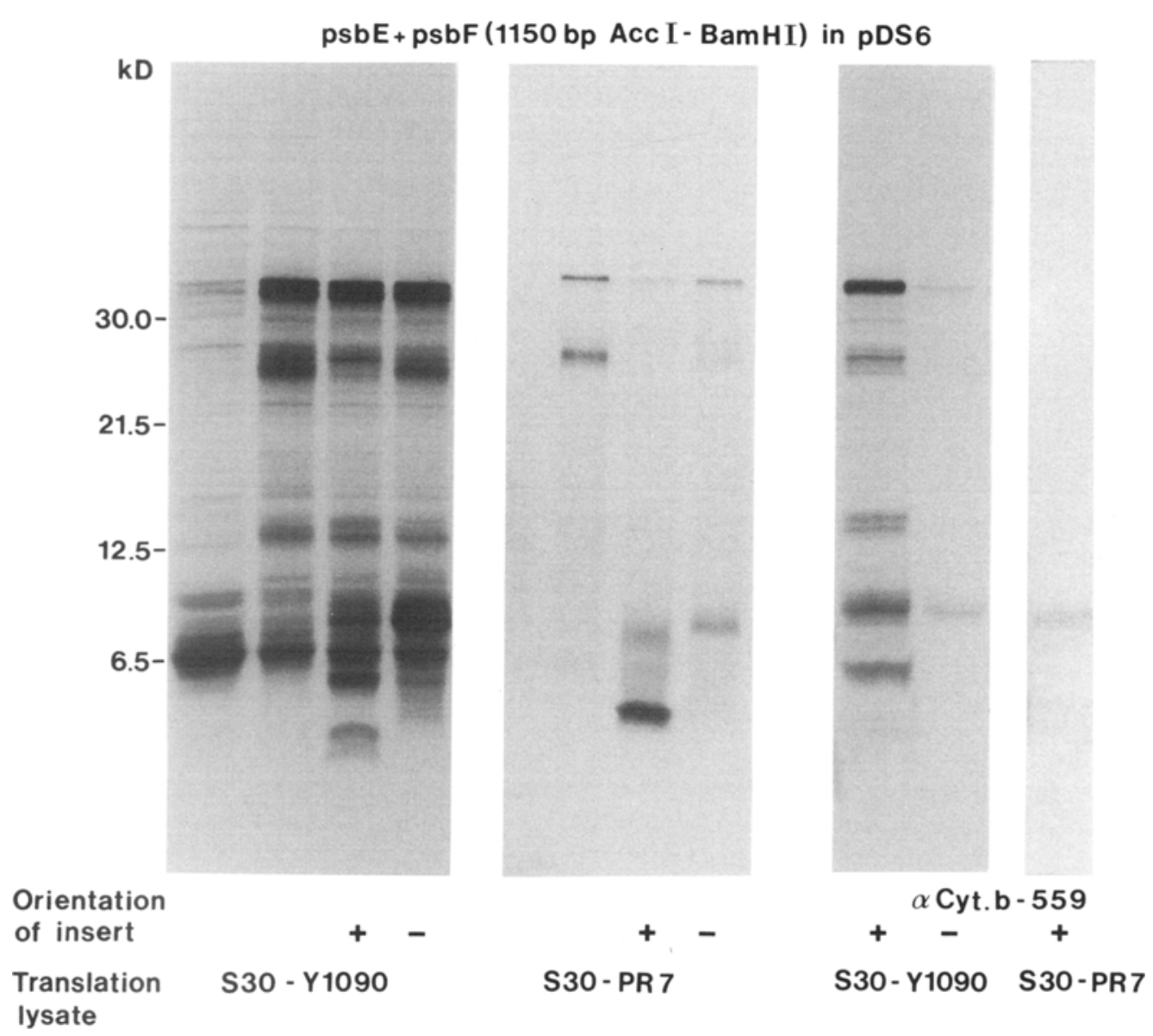

Figure 2. In vitro expression of psbE and psbF using recombinant pDS6 as templates. The $1150 \mathrm{bp}$ Accl-BamHI fragment was inserted into pDS6 in correct $(+)$ or inverse $(-)$ orientation with respect to the T5 promoter of the vector-

Transcripts obtained from recombinant pDS6 with E. coli RNA-polymerase were translated in two different $\$ 30$ lysates: The first one was prepared from the E. coli strain Y 1090 and the second one was prepared from E. coli strain PR7 (2). The Y1090 S30 lysate shows considerable endogenous protein synthesis by itself and with the transcripts from the vector without insert (lanes 1, 2 from left). The PR7 lysate shows no (lane 5) and with vector derived RNA little endogenous protein synthesis (lane 6). ${ }^{35} \mathrm{~S}$-methionine labelled translation products were autoradiographed after separation on $18 \%(\mathrm{w} / \mathrm{v})$ acrylamide gels (7).

In vitro translation products derived from recombinant pDS6 were immunoprecipitated with a monoclonal antibody (mAb6A5) specific for the C-terminal part of the $9.4 \mathrm{kD}$ polypeptide of cytochrome $b-559$ ( $\alpha$-Cyt. $b-559)$. In case of recombinant pDS6 with the insert in correct orientation immunoprecipitation of translates obtained in the Y1090 lysate is compared to immunoprecipitation of translates obtained in the PR7 lysate. The $9.4 \mathrm{kD}$ apoprotein recognized by the antibody is indicated by an arrow. ${ }^{14} \mathrm{C}$-labelled methylated molecular weight markers comprised carbonic anhydrase $(30 \mathrm{kD})$, soybean trypsin inhibitor $(21.5 \mathrm{kD})$, cytochrome $c(12.5 \mathrm{kD})$ and aprotinin $(6.5 \mathrm{kD})$

stopcodon (Figure 4) was chosen for in vitro expression. The fragment was isolated from recombinant $\mathrm{pUC} 13$ by digestion with BamHI and SacI, blunt-ended by T4 DNA-polymerase and inserted into the SmaI sites of pDS6 and pGem3. In the case of recombinant pSD6 both 


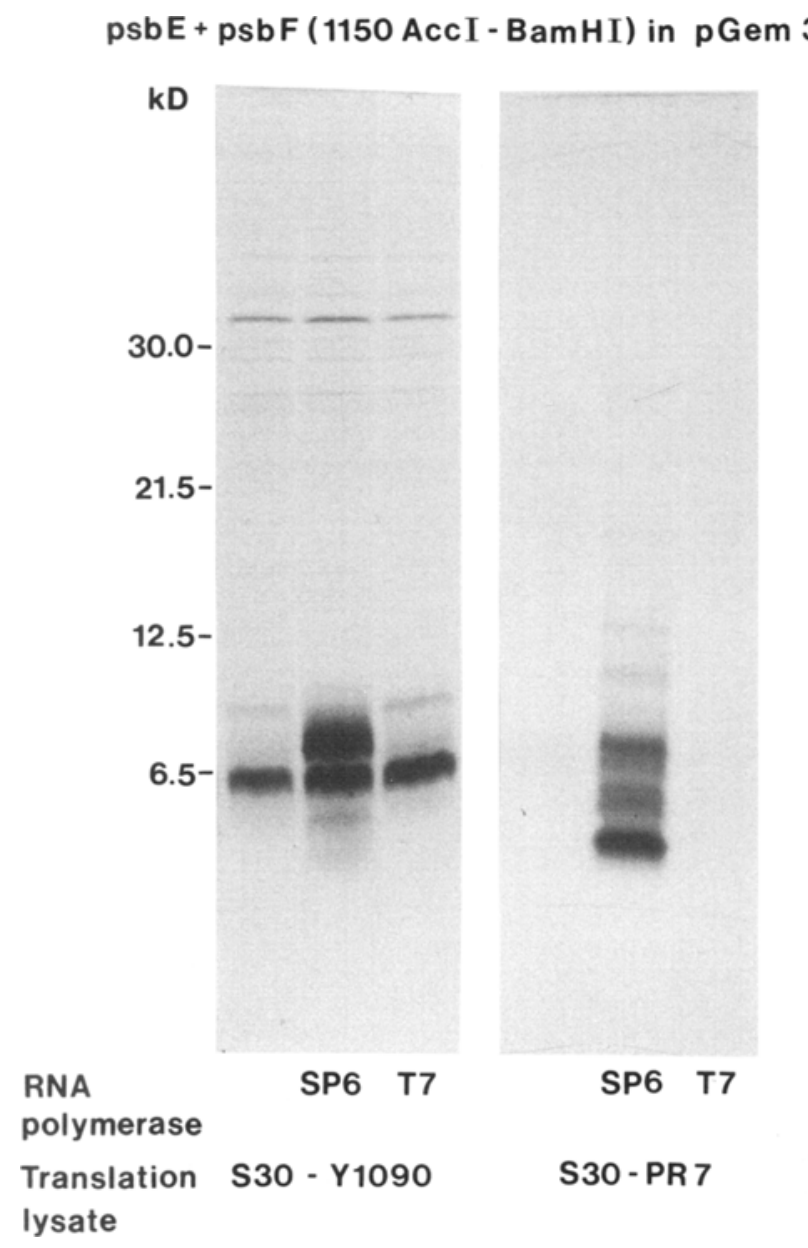

Figure 3. In vitro expression of the psbE and psbF genes included in the $1150 \mathrm{bp}$ Accl-BamHI fragment in the twin promoter system pGem3. Transcription was done with SP6 RNA-polymerase and as a control with T7 RNA-polymerase. For translation an S30 lysate from E. coli strain Y 1090 (left) and from E. coli strain PR7 were used.

${ }^{35}$ S-methionine labelled translation products were autoradiographed after separation on $18 \%(\mathrm{w} / \mathrm{v})$ acrylamide gels (7). Lanes 1 and 4 from reaction mixtures without vector derived RNA. Molecular weight markers indicated on the left were as in Figure 2.

orientations of the insert with respect to the T5 promoter were compared. In the case of recombinant pGem 3 transcription with SP6 RNApolymerase was compared to transcription with T7 RNA-polymerase.

pDS6 with the 400 bp Bal31 fragment in correct orientation gave rise to the synthesis of a protein with a molecular weight of about $4 \mathrm{kD}$ (Figure 5). If the vector contained the same DNA-fragment in inverse orientation no in vitro product could be detected (Figure 5).

With the insert of the $1150 \mathrm{bp} \mathrm{AccI-BamHI}$ fragment in pDS6 (section 3.1.1) the distance between the $\mathrm{T} 5$ promoter and the startcodon of psbE is about $150 \mathrm{bp}$ but it is only $40 \mathrm{bp}$ in the case of the inserted $400 \mathrm{bp} \mathrm{Bal} 31$ fragment. In order to examine whether a longer distance between promoter and the ATG-startcodon is required for expressing the genes and may reestablish the synthesis of the larger protein 


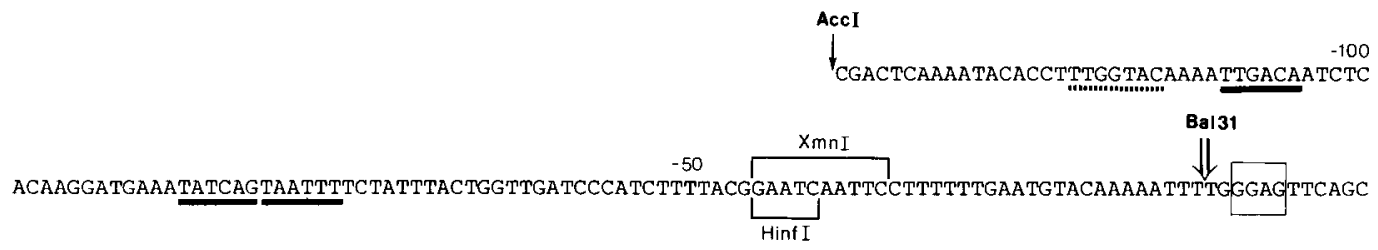

1150

ATG TCT GGA AGC ACG GGA GAA CGT TCT TTT GCT GAT ATT ATT ACC AGT ATT CGA TAC TGG GTT ATT CAT AGC ATT Met Ser Gly Ser Thr Gly Glu Arg Ser phe Ala Asp Ile Ile Thr Ser Ile Arg Tyr Trp Val Ile His Ser Ile

ACT ATA CCT TCC CTA TTC ATT GCG GGT TGG TTA TTT GTC AGT ACG GGT TTA GCT TAT GAC GTG TTT GGA AGT CCT Thr Ile pro Ser Leu phe Ile Ala Gly Trp Leu phe Val Ser Thr Gly Leu Ala Tyr Asp val phe Gly Ser pro 1

ATG ACG TGT TTG GAA GTC Met Thr Cys Leu Glu Val

\footnotetext{
AGG CCA AAC GAG TAT TTC ACG GAA AGC CGA CAA GGA ATT CCG TTA ATA ACC GAC CGT TTt GAT TCT TTA GAA CAA Arg Pro Asn Glu Tyr Phe Thr Glu Ser Arg Gln Gly Ile pro Leu Ile Thr Asp Arg Phe Asp Ser Leu Glu Gin CTA GGC CAA ACG AGT ATT TCA CGG AAA GCC GAC AAG GAA TTC CGT TAA

Leu Gly Gln Thr Ser Ile Ser Arg Lys Ala Asp Lys Glu Phe Arg
}

CTC GAT GAA TTT AGT AGA TCC HaeII Leu Asp Glu Phe Ser Arg Ser Phe Thet Thr Ile Asp Arg Thr Tyr Pro Ile Phe Thr Val Arg ATG AAT TTA GTA GAT CCT TTT AGG AGG CCC TCA Met Asn Leu Val. Asp Pro Phe Arg Arg Pro Ser

TGG CTG GCT ATT CAC GGA CTA GCT GTA CCT ACT GTT TTT TTC TTG GGA TCA ATA TCA GCA ATG CAG TTC ATC CAA Trp Leu Ala Ile His Gly Leu Ala Val pro Thr val phe phe Leu Gly Ser Ile Ser Ala Met Glu phe Ile Gln

CGA TAA ACCAAATTCCAACTATAGAACTATGACACAATCAAACCCGAATGAACAAAATGTTGAATTGAATCGTACCAGTCTATACTGGGGTTTATTA Arg

CTCATTTTTGTACTTGCTGTTTTATTTTCCAATACTTCTTCAATTGAGAGAAAGAAAGAGACTAACAAG

Figure 4. Nucleotide sequence of the chloroplast DNA region containing the psbE and psbF genes. Relevant restriction sites are indicated and the derived amino acid sequences for the two genes given. Numbering starts at the first base of the psbE startcodon. Putative ribosomal binding sites are boxed. Amino acids recognized by the monoclonal antibody (mAb 6A5) are underlined by a wavy line. Double-lined arrows indicate the positions up to which non-coding sequences adjacent to the genes were degraded by Bal31 exonuclease treatment. Two-out-of phase ATG codons within the psbE nucleotide sequence are indicated by horizontal brackets and their corresponding reading frames are written underneath the normal amino acid sequence of the psbE product.

having the molecular weight of about $9 \mathrm{kD}$, the 400 bp Bal31 fragment was elongated 5' upstream of the ATG-codon of psbE. For this purpose a $36 \mathrm{bp}$ fragment was released from the polylinker region of pUC18 (20), blunt-ended and ligated to the $400 \mathrm{bp}$ Bal31 fragment. The increase in the distance between promoter and startcodon of psbE hardly altered the pattern of translation products but it stimulated the production of the about $4 \mathrm{kD}$ protein dramatically (Figure 5).

If the appropriate $\mathrm{pGem} 3$ vector was used for 


\section{psbE+psbF \\ (400 bp Bal 31)}

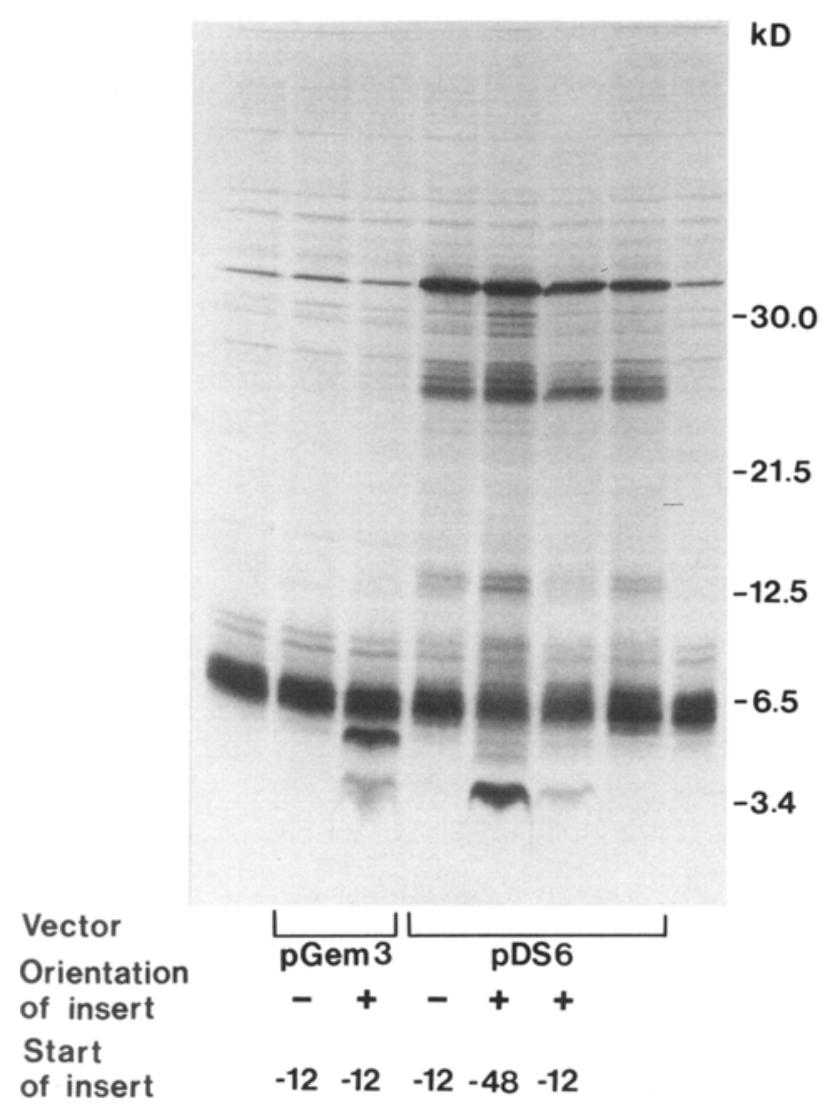

Figure 5. In vitro expression of psbE and psbF from a $400 \mathrm{bp}$ Bal 31 fragment inserted into $\mathrm{pGem} 3$ and pDS6. From pGem 3 the insert was transcribed by SP6 polymerase when placed in correct orientation ( + ). In pDS6 the $400 \mathrm{bp}$ Bal31 fragment was inserted in correct $(t)$ and inverse (-) orientation with respect to the T5 promoter and was transcribed by E. coli RNA-polymerase. The unmodified insert started 12 nucleotides upstream of the psbE startcodon (Figure 4). A modified insert with a 5' extension of 36 bp had 48 nucleotides upstream of the ATG-startcodon. ${ }^{35} S$-labelled translation products were obtained in an $\$ 30$ lysate from Y $1090 \mathrm{E}$. coli cells. Controls without vector derived RNA are given in the leftmost and rightmost lanes. The proteins were separated on an $18 \%$ (w/v) polyacrylamide gel (7). Molecular weight markers indicated on the right of the pertinant autoradiogram were as in Figure 2 and included the B-chain of insulin (3.4 kD).

in vitro expression of the $400 \mathrm{bp} \mathrm{Bal31}$ fragment, a $5 \mathrm{kD}$ molecular weight product was prominent and less of the $4 \mathrm{kD}$ polypeptide was obtained (Figure 5). Additionally a smaller polypeptide of about 2-3 $\mathrm{kD}$ molecular weight was synthesized (Figure 5). No proteins were synthesized if T7 polymerase instead of SP6 polymerase was used (Figure 5). A translation product of $9 \mathrm{kD}$ molecular weight was not obtained with these constructs. None of the translation products obtained from the $400 \mathrm{bp}$ Bal31 fragment was immunoprecipitable with the monoclonal antibody mAb 6A5 (data not shown).

\subsection{Expression of psbE}

In order to express psbE independently from psbF, a $270 \mathrm{bp}$ fragment obtained by partial 


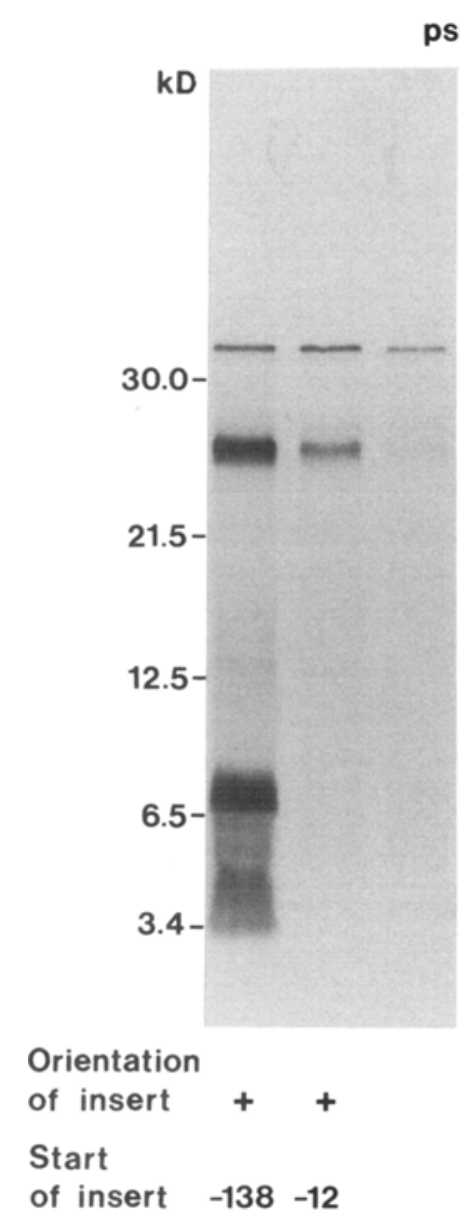

psbE
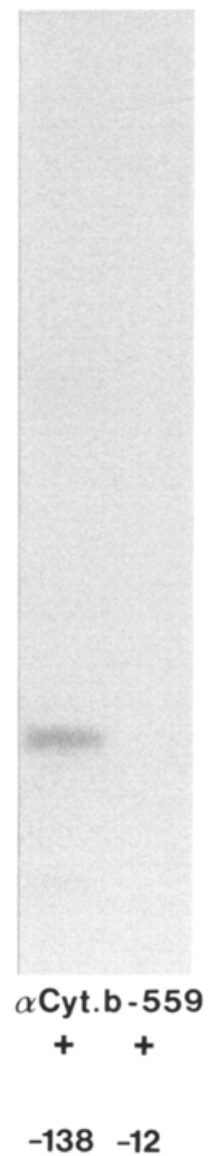

psbF

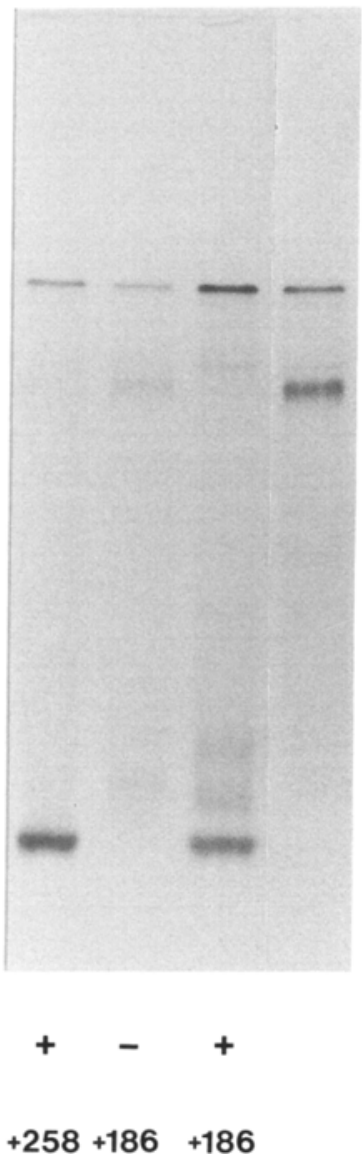

Figure 6. Separate in vitro expression of psbE and psbF using recombinant pDS6 plasmids in which the DNA-fragments were inserted in correct $(+)$ or inverse $(-)$ orientation with respect to the T5 promoter. The 5 ' end of the inserted DNA-fragments relative to the startcodon of $\mathrm{psbE}$ is given according to the numbering of the nucleotide sequence (Figure 4). The ATG codon for $\mathrm{psbF}$ is at $+263 .{ }^{35} \mathrm{~S}$-methionine labelled translation products obtained in PR7 lysates were autoradiographed after separation on 18\% (w/v) polyacrylamide gels (7). Translation products from psbE were immunoprecipitated with a monoclonal antibody specific for cytochrome $b-559$ ( $\alpha$-Cyt. $b-559$ ). The protein recognized by the antibody is indicated by an arrow. Molecular weight markers indicated on the left were as in Figures 2 and 5. Lanes 3 and 9 are controls from translation assays with RNA derived from vectors without inserts.

digestion of the $400 \mathrm{bp}$ Bal31 fragment with HaeIII was inserted into the SmaI sites of pDS6 and pGem3 (270 bp Bal31-HaelII) (Figures 1 and 4, Table I). Neither the recombinant pDS6 with the insert in correct orientation nor the recombinant pDS6 with the insert in inverse orientation gave rise to any polypeptide in the S30 lysate (Figure 5). No expression was observed by using the pertinent pGem 3 either (data not shown).

In order to test whether possible regulatory sequences 5 ' upstream of the psbE gene are necessary for expression another fragment was used instead. It included an additional $135 \mathrm{bp}$ sequence 5' upstream of the psbE startcodon and was obtained by ligating a 300 bp AccIEcoRI fragment to the $70 \mathrm{bp}$ EcoRI-HaeIII fragment (Figures 1 and 4). The first fragment 


$$
\begin{aligned}
& -120 \quad-100 \\
& \text { TITGGTACAAAATTGACAATCTCACAAGGATGAAATATCAGTAATTT }
\end{aligned}
$$

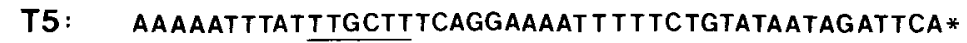

T7:

GAAATTAATACGACTCACTATAG*

SP6:

CGGCTACAATTA

atacataACCtTATgtatcataCaCatacgattTaggtgacactatag*

Figure 7. Nucleotide sequence of a region preceding the psbE gene and containing the putative cytochrome $b-559$ promoter, compared to the nucleotide sequences of the coliphage T5 promoter serving for $E$. coli RNA-polymerase in the pDS6 expression system (18) and the promoters for T7 RNA-polymerase (6) and SP6 RNA-polymerase (13) used in the twin promoter system pGem3. Hexameric sequences resembling the "-10" and "-35" consensus sequences of bacterial promoters (15) are underlined. A broken line indicates an additional possible regulatory sequence in the nucleotide sequence preceding the psbE gene (see also Figure 4). Asterisks indicate the nucleotides at which the RNA chains begin.

was released by digestion of the $1.5 \mathrm{kbp}$ EcoRI fragment (see ref. 11, Figure 3) with AccI. The latter fragment containing the terminal part of psbE was obtained by digestion of the $350 \mathrm{bp}$ EcoRI fragment (see ref. 11, Figure 3) with HaeIII. The 370 bp ligation product was subcloned into pGem3 cut with AccI and SmaI, whereafter the fragment was reisolated from recombinant $\mathrm{pGem} 3$ by digestion with PstI and PvuII. This larger segment of $460 \mathrm{bp}$ in length was stepwise inserted into pDS6 linearized by PstI and HindIII: After ligation of the PstI ends the remaining HindIII tail of the vector was blunt-ended and ligated to the blunt-end of the insert. The resulting plasmid contained the psbE gene in correct orientation with respect to the T5 promoter (Figure 1). This recombinant pDS6 vector as well as the recombinant pGem 3 (data not shown) gave rise to the synthesis of a $9 \mathrm{kD}$ protein which is immunoprecipitated by the monoclonal antibody specific for cytochrome b-559 (Figure 6).

\subsection{Expression of psbF}

For expression of psbF alone the $350 \mathrm{bp}$ EcoRI fragment (ref. 11, Figure 3) was inserted into the EcoRI cloning sites of pDS6 and pGem3 (Figure 1, Table I). The recombinant pDS6 with the correctly inserted fragment gave rise to the synthesis of a $4 \mathrm{kD}$ polypeptide (Figure 6). No proteins were obtained from recombinant pDS6 with the fragment in inverse orientation (Figure 6). If the recombinant pGem3 was transcribed with SP6 RNA-polymerase also a $4 \mathrm{kD}$ polypeptide was synthesized (data not shown).

A smaller $200 \mathrm{bp}$ fragment was released from the $350 \mathrm{bp}$ EcoRI fragment by digestion with HaellI and Hinfl (Figures 1 and 4). Since this fragment did not contain a complete ribosomal binding site it had to be subcloned into the modified vector pDS6-RBSII. To begin with it was inserted into the SmaI site of pGem3 and subsequently released again with BamHI and EcoRI. The BamHI end was ligated to pDS6RBSII linearized with BamHI and PstI. After blunt-ending the EcoRI and PstI tails the ends were joined. The resulting plasmid contained the insert automatically in the correct orientation with respect to the T5 promoter. The recombinant plasmid gave rise to the production of a single $4 \mathrm{kD}$ polypeptide during translation (Figure 6). No proteins were obtained if the appropriate pGem 3 vector without a ribosomal binding site was used instead (data not shown).

Neither the $4 \mathrm{kD}$ polypeptide translated from the transcript of the $350 \mathrm{bp} \mathrm{EcoRI} \mathrm{fragment} \mathrm{nor}$ the corresponding polypeptide obtained with the smaller psbF fragment were recognized by the monoclonal antibody specific for the C-terminal end of the cytochrome $b-559,9.4 \mathrm{kD}$ polypeptide (data not shown).

The results on the in vitro expression of the 
various DNA-fragments containing psbE and psbF either in the same or separate plasmids are summarized in Table I.

\section{DISCUSSION}

In vitro expression of the two cytochrome $b-559$ genes of barley employed to begin with a $1150 \mathrm{bp}$ AccI-BamHI fragment containing the two genes in tandem with 138 nucleotides 5' upstream and a 3' extension of about 470 nucleotides. Transcription by E. coli RNA-polymerase and phage SP6 RNA-polymerase and translation in an E. coli lysate yielded in addition to the expected $9.4 \mathrm{kD}$ and $4.5 \mathrm{kD}$ apoproteins of cytochrome $b-559$ two additional polypeptides with molecular weights of about 5 and less than $4 \mathrm{kD}$ (Figures 2 and 3). Only the $9.4 \mathrm{kD}$ in vitro translation product is recognized by the monoclonal antibody $\mathrm{mAb} 6 \mathrm{~A} 5$. By investigating the reaction of this antibody (19) with cytochrome $b-559$ apoproteins from different plant species having slightly different primary structure and with a synthetic tredecapeptide corresponding to residues $69-81$ of the barley apoprotein I, the residues $80-81$ (Ser-Arg) in the C-terminus of the apoprotein were identified as major constituents of the epitope recognized by mAb 6A5 (O. VALLON, personal communication). Immunoprecipitation with this antibody identifies the $9.4 \mathrm{kD}$ polypeptide obtained by in vitro translation as product of the $\mathrm{psbE}$ gene.

If the $1150 \mathrm{bp} \mathrm{Accl-BamHI}$ fragment is inserted in pDS6 in inverse orientation with respect to the $\mathrm{T} 5$ promoter, unexpectedly also a translation product of about $9 \mathrm{kD}$ is obtained (Figure 2). Its identity with apoprotein I could be shown by immunoprecipitation with the monoclonal antibody mAb 6A5 (Figure 2). If the analogous pGem3 plasmid is transcribed with T7 RNApolymerase instead of SP6 RNA-polymerase, however, no in vitro translation product has been observed (Figure 3). Actually, there is no open reading frame which might code for a protein of this size on the opposite strand of the $1150 \mathrm{bp}$ AccI-BamHI fragment containing the psbE and psbF genes. Most likely cytochrome $b$-559 promoter sequences (cf. 11) located 5' upstream of psbE (Figures 4 and 7) serve as promoter for the E. coli RNA-polymerase but not for the phage T7 RNA-polymerase. Both the T7 and SP6 phage RNA-polymerases used for transcription of DNA inserted in pGem 3 have highly specific promoter sequences which do not resemble those recognized by the E. coli RNApolymerase $(3,6)$. As shown in Figure 7 there is little similarity between the nucleotide sequences of the SP6 (3) or T7 (6) phage promoters and the consensus sequences of bacterial promoters. On the other hand, the T5 promoter of pDS6 serving for E. coli RNA-polymerase and the putative cytochrome $b-559$ promoter have typical bacterial "- 35 " and "- 10 " sequences (15).

None of the other fragments tested for in vitro expression of psbE and psbF when inserted into pDS6 in inverse orientation seem to be transcribed (Table I).

In vitro expression of the two cytochrome $b-559$ genes psbE and psbF together was further studied with a 400 bp Bal31 fragment in which the 5' upstream region was truncated to position -12 from the psbE startcodon and the 3' downstream region to 10 nucleotides from the stopcodon of the psbF gene. With this fragment in vitro synthesis of the $9.4 \mathrm{kD}$ apoprotein was no longer possible despite the presence of a GGAG ribosomal binding site in front of the psbE gene (Figures 4 and 5). In vitro expression of the recombinant pDS6 plasmid yielded only a polypeptide of about $4 \mathrm{kD}$ molecular weight (Figure 5) which is considered to be apoprotein II. Since STUEBER et al. (18) had reported that the distance between the $\mathrm{T} 5$ promoter and the startcodon of inserted genes affects the efficiency of the system, the distance between the startcodon of the psbE gene and the T5 promoter was extended by $36 \mathrm{bp}$. This modification dramatically increased the synthesis of the $4 \mathrm{kD}$ polypeptide but did not elicit the expression of the psbE gene(Figure 5). This result suggests that specific sequences preceding the psbE gene rather than a certain distance between T5 promoter and startcodon of psbE are necessary for expression of the gene.

Unlike transcription by E. coli RNA-polymerase the use of SP6 RNA-polymerase permitted the synthesis of two additional polypeptides of $5 \mathrm{kD}$ and less than $4 \mathrm{kD}$, respectively (Figure 5). These two additional polypeptides are likely 
to be translated from the out-of-phase ATG codons in position +131 and +230 (Figure 4). The first of these reading frames starting with position +131 ends with a TAA stopcodon at position +194 and would yield a polypeptide of 21 amino acids which calculates to a molecular weight of $2.4 \mathrm{kD}$. The out-of-phase reading frame starting with the ATG at nucleotide +230 would extend the $\mathrm{N}$-terminus of apoprotein II with a presequence of 11 additional amino acid residues and result in a polypeptide with a molecular weight of $5.7 \mathrm{kD}$. This chimaeric protein would not contain the Ser-Arg dipeptide recognized by the monoclonal antibody $\mathrm{mAb}$ 6A5 and explains why the antibody did not precipitate this protein, whether SP6 RNA-polymerase is used on the $400 \mathrm{bp} \mathrm{Bal} 31$ fragment in the twin promoter system (cf. Figure 5) or E. coli RNA-polymerase on the $1150 \mathrm{bp}$ AccI-BamHI fragment in the pDS6 vector (cf. Figure 2). Expression vectors containing the psbE gene alone with a 138 nucleotides long "leader sequence" in front of the psbE startcodon provided an immunoprecipitable in vitro translation product of $9.4 \mathrm{kD}$ molecular weight (Figure 6). No protein was synthesized in vitro if the 5 , region was truncated to position -12 in front of the startcodon (Figure 6). This result is consistent with the absence of psbE expression in the case of the $400 \mathrm{bp}$ Bal31 fragment containing both genes and truncated to position -12 in front of the psbE startcodon (Table I). As concluded from results obtained by the $36 \mathrm{bp} 5$ ' extension of the $400 \mathrm{bp} \mathrm{Bal} 31$ fragment specific sequences preceding the psbE gene are necessary for expression of the gene.

For expression of the psbF gene alone two different fragments have been employed, the $350 \mathrm{bp}$ EcoRI fragment containing in front of psbF the terminal part of the psbE gene and its smaller 200 bp HaelII-Hinf derivative with only 6 nucleotides in front of the psbF startcodon. Both yielded an in vitro translation product of $4.5 \mathrm{kD}$ molecular weight. Since $\mathrm{psbF}$ alone can direct the synthesis of this protein it identifies it as cytochrome $b-559$ apoprotein II. This protein is not recognized by the monoclonal antibody mAb 6A5.

In conclusion, the two apoproteins of cytochrome $b-559$ with molecular weights of 9.4
$\mathrm{kD}$ and $4.5 \mathrm{kD}$ have been identified among the in vitro translation products obtained by expression of the $1150 \mathrm{bp} \mathrm{Accl-BamHI}$ fragment containing both genes and by independent expression of the separated psbE and psbF genes.

Differences between chloroplast RNA-polymerase and E. coli RNA-polymerase (8) or special features of the chloroplast translation system will have to be explored in order to understand why translation products using internal out-of-phase initiator codons have been obtained in the present experiment.

The smallest heme containing subunit of cytochrome $b-559$ is considered to be a heterodimer of the two apoproteins in which heme is ligated by a histidine residue of each chain. For heme binding studies and in vitro assembly of the polypeptides into subunits the production of the apoproteins is recommended from the recombinant pDS6 plasmid with the psbE gene contained in the $370 \mathrm{bp}$ AccI-HaeIII fragment and from the recombinant pDS6-RBS II plasmid with the psbF gene contained in the $200 \mathrm{bp}$ HaeIII-Hinfl fragment.

\section{ACKNOWLEDGEMENTS}

I would like to thank Professor DITER vON WETTSTEIN for stimulating discussions, encouragement and critical review of the manuscript. I am indebted to GUNILla HøYER-HANSEN, Hanne Them Nielsen, Lise Trillot, Nina RasMUSSEN, ANN-SOFi SteINHOLTZ and Professor DITER VON WETTSTEIN for technical help during preparation of the manuscript. The work was supported by an EMBO Fellowship.

\section{REFERENCES}

1. BARD, J.D.J., D.P. Bourque \& D. Zaituin: Coupled transcription-translation in chloroplast lysates. Methods in Enzymology 118, 270-281 (1986)

2. Botromley, W. \& P.R. Whitfeld: Cell-free transcription and translation of total spinach chloroplast DNA. Eur. J. Biochem. 93, 31-39 (1979)

3. Butler, E.T.\& M.J. ChamberlaIN: Bacteriophage SP6-specific RNA-polymerase. II. Mapping of SP6 DNA and selective in vitro transcription. J. Biol. Chem. 257, 5779-5788 (1982)

4. Chamberlain, J.P.: Fluorographic detection of radioactivity in polyacrylamide gels with the wa- 
ter-soluble fluor, sodium salicylate. Anal. Biochem. 98, 132-135 (1979)

5. CHEN, E.Y.\& P.H. SEEBURG: Supercoil sequencing: a fast and simple method for sequencing plasmid DNA. DNA 4, 165-170 (1985)

6. DUNN, J.J. \& F.W. STUDIER: Nucleotide sequence from the genetic left end bacteriophage T7 DNA to the beginning of gene 4. J. Mol. Biol. 148, 303-330 (1981)

7. FLING, S.P. D.S. Gregerson: Peptide and protein molecular weight determination by electrophoresis using a high-molarity tris buffer system without urea. Anal. Biochem. 155, 83-88 (1986)

8. HaNley-Bowdoin, L. \& N.H. ChUa: Chloroplast promoters. Trends in Biochem. Sci. 12, 67-70 (1987)

9. Herrmann, R.G., J. Alt, B. Schiller, W.R. WIDGER \& W.A. CRAMER: Nucleotide sequence of the gene for apocytochrome b-559 on the spinach plastid chromosome: implications for the structure of the membrane protein. FEBS Lett. 176, 239-244 (1984)

10. Høyer-Hansen, G., L. SKou Hønberg \& P.B. HøJ: Probing in vitro translation products with monoclonal antibodies to a $15.2 \mathrm{kD}$ polypeptide subunit of photosystem I. Carlsberg Res. Commun 50, 211-221 (1985)

11. KRUPINSKA, K \& S. BERRY-LOWE: Characterization and in vitro expression of the cytochrome $b-559$ genes of barley I. Localization and sequence of the genes. Carlsberg Res. Commun. 53, 43-55 (1988)

12. Maniatis, T., E.F. FritsCh \& J. SAMBROOK: Molecular cloning. Cold Spring Harbor Laboratory Press, New York (1982)

13. Melton, D.A., P.A. Krieg, M.R. Rebagliati, T. MANIATIS, K. ZINN \& M.R. GREEN: Efficient in vitro synthesis of biologically active RNA and RNA hybridization probes from plasmids containing a bacteriophage SP6 promoter. Nucl. Acids Res. 12, 7035-7056 (1984)

14. Pritchard, R.H \& I.B. Holland: Preparation of the components of an $\mathrm{E}$. coli in vitro transcription/ translation system. C.IV. In: Basic Cloning Techniques. Blackwell Scientific Publications, Oxford, pp. 137-142 (1985)

15. ROSENBERG, M.\& D. COURT: Regulatory sequences involved in the promotion and termination of RNA transcription. Ann. Rev. Genet. 13, 319-353 (1979)

16. SANGER, F., S. NickleR \& A.R. COULSON: DNA sequencing with chain-terminating inhibitors. Proc. Natl. Acad. Sci. USA 74, 5463-5467 (1977)

17. STUEBer, D. \& H. BUjaRd: Transcription from efficient promoters can interfere with plasmid replication and diminish expression of plasmid specified genes. EMBO J. 1399-1404 (1982)

18. Stueber, D., I IBrahmi, D. CutLer, B. DobrerSTEIN \& H. BUJARD: A novel in vitro transcriptiontranslation system: accurate and efficient synthesis of single proteins from cloned DNA sequences. EMBO J. 3, 3143-3148 (1984)

19. Vallon, O., G. Høyer-Hansen \& D.J. Simpson: Photosystem II and cytochrome $b-559$ in the stroma lamellae of barley chloroplasts. Carlsberg Res. Commun. 52, 405-421 (1987)

20. VIEIRA,J. \&J.MESSING: The pUCplasmids, an M13 $\mathrm{mp}^{7}$-derived system for insertion mutagenesis and sequencing with synthetic universal primers. Gene 19, 259-268 (1982)

21. Widger, W.R., W.A. Cramer, M. Hermodson * R.G.HERRMANN: Evidence for a hetero-oligomeric structure of the chioroplast cytochrome b-559. FEBS Lett. 191, 186-190 (1985)

22. ZuBAY, $G$ : In vitro synthesis of protein in microbial systems. Ann. Rev. Gen. 7, 267-288 (1973) 